\title{
Characterizing the long-term taxonomic and functional variability of a stream fish assemblage
}

\author{
I. Czeglédi ${ }^{1}$ and Tibor Erős ${ }^{2, *}$
}

With 4 figures and 3 tables

\begin{abstract}
While much research has been devoted to characterizing congruency in the spatial distribution of taxonomic and functional structure, the temporal aspect of this relationship is poorly known. We examined taxonomic and trophic function based variability of a stream fish assemblage using a 12-year data set of spring and summer surveys. We found the occurrence of the most abundant species was persistent, while their relative abundance was variable. Rare, satellite species formed less than $3 \%$ of the assemblage and contributed little to variations in relative abundance. Assemblage level trophic function proved to be relatively stable across years, but showed clear seasonality. The pattern of long-term taxonomic composition indicated that seasonal differences in trophic function were primarily due to a switch to alternate food resources by some species between seasons and not due to periodic immigration/emigration of fish with different functions. Overall, our study showed significant directional changes in taxonomic variability in time, but relative stability in trophic function, and suggested that local processes (i.e. population dynamics of resident species and seasonality of food resources) influenced assemblage dynamics, while the relative role of regional scale processes (periodic immigration/emigration) was low. The study also suggests considering more direct measures for evaluating the assemblage level function of fish than using rigid guild-based categorizations.
\end{abstract}

Key words: temporal variability, stability, trophic function, feeding guilds, community organization.

\section{Introduction}

Assessing congruency between taxonomic and functional structure has become an important avenue of research, highlighting the need for a more intensive application of trait-based approaches in understanding the structure and function of ecosystems (McGill et al. 2006, Webb et al. 2010). Trait-based approaches, which characterize organisms based on their biological attributes (e.g. feeding, life-history traits), have been advocated, because they can be more directly linked to ecosystem functions (e.g. decomposition, food web organization) in a taxon independent manner. Therefore, they are more easily comparable across ecosystems, and may also provide stronger linkages between community and ecosystem ecology (McGill et al. 2006, Webb et al. 2010).

While much research has been devoted to the determination of temporal variability based on taxonomic structure, less is known about the functional variability of assemblages (but see e.g. Grossman et al. 1982, Berg \& Bengtsson 2007). We define functional variability as the temporal variability in the importance of predefined functional roles, which may determine community or ecosystem level processes. The relationship between long-term taxonomic and functional variability is especially poorly known. In fact, four extreme cases (i.e. scenarios) are possible

\footnotetext{
Authors' addresses:

${ }^{1}$ Department of Hydrobiology, University of Debrecen, Egyetem tér 1., H-4032 Debrecen, Hungary

${ }^{2}$ Balaton Limnological Institute, MTA Centre for Ecological Research, Klebelsberg K. u. 3., H-8237, Tihany, Hungary

*Corresponding author: eros.tibor@okologia.mta.hu
} 
in the rough scale categorization of the temporal congruency between taxonomic and functional variability. The outcome depends on the relative importance local (e.g. niche based) and regional scale (e.g. colonization dynamics) processes play in community dynamics and the variability in the function of assemblage constituting species. In the first case both taxonomic and functional structures are (relatively) stable in time. This case is possible when species composition and abundance relationships remain stable and functional roles of assemblage constituent species remain the same over time. This model suggests the importance of local scale community dynamics, with no or little role for colonization processes. In the second case taxonomic structure is stable whereas functional structure shows temporal variations. This is possible when the colonization rate of new species is low, but the functional role of species change over time due to changes in temporally variable environmental conditions or the quantity of resources they use (e.g. food resources). In the third case both taxonomic and functional structure may show temporal variability. In this model both local scale community variability and/or larger scale colonization processes have significance. Here, functional variability may reflect temporal changes in taxonomic structure and/or changes in species functions in time. Finally in the fourth case taxonomic structure may show variability, while overall functional roles remain stable over time. This is possible when species' extinction-colonization dynamics do not yield functional changes in the community (i.e. immigrating species have the same role as species which go "extinct" or emigrate from the community).

Streams are exceptionally dynamic ecosystems, where hydrologic variability (e.g. floods and droughts) have a substantial role in shaping the organization and dynamics of communities (Poff et al. 1997). Although there is a general consensus between most stream fish ecologists that the temporal variability of stream fish assemblages is mainly governed by the variability of the flow regime (Grossman et al. 1998, Magalhães et al. 2007, Grossman \& Sabo 2010, Taylor 2010), recent landscape based views of stream ecosystems additionally suggest that colonization processes can have an overarching role over instream habitat variability in influencing temporal variability (Roberts \& Hitt 2010). Nevertheless, characterization of long term (>10 years) temporal variability within individual stream systems are still relatively rare and these are constrained largely to the quantification of taxonomic variability (e.g. Grossman et al. 1990, Eby et al. 2003).
In this study, we examined temporal variability in the taxonomic and functional structure of a stream fish assemblage in a near natural stream system (Kemence stream, NE Hungary). For determining functional structure, we used the trophic role of fishes because this function may provide one of the most important and most direct links to ecosystem processes (Petchey $\&$ Gaston 2006). Our questions were as follows. 1) What are the main trophic functions of fishes in the Kemence stream and how does food composition change between species, size groups and seasons? 2) How does the taxonomic and functional structure of the assemblage change over time during a twelve year period? 3) In the light of these results, what is the role of local vs regional scale processes in shaping taxonomic and functional variability of the assemblage in this system?

\section{Material and methods}

\section{Study area}

Our study area was a long term monitoring site in the Kemence stream, a third order (Strahler's classification) submontane stream located in the Börzsöny Mts, Hungary (Erös \& Grossman 2005a, Erős \& Schmera 2010). At this downstream section the stream has a well developed riffle-pool geomorphology with stone and gravel as the dominant substrata. The dominant trees along the stream margin are poplar (Populus alba (L.)) and alder (Alnus glutinosa (L.)). Stream width at this study site averaged $\sim 5 \mathrm{~m}$; mean water depth in representative riffle and pool habitats averaged $\sim 10 \mathrm{~cm}$ and $\sim 50 \mathrm{~cm}$, respectively. Detailed data on the hydrological and morphological characteristics of representative riffle and pool patches can be found in Erös \& Grossman (2005a). The study site on the Kemence stream located $\sim 1 \mathrm{~km}$ above its confluence with the Ipoly River. Fish can freely swim from the species rich Ipoly River to the Kemence stream.

\section{Sampling methodology}

We used our long term monitoring data set for characterising taxonomic variability, which spanned a 12 year period from 2000 through 2011 . The $150 \mathrm{~m}$ long study reach was sampled using a two-person backpack electrofishing team $(350-450 \mathrm{~V}$, Pulsed Direct Current) slowly moving upstream while fishing the whole study area (i.e. from bank to bank). Four seasonal samples (spring, early summer, late summer, autumn) were collected with multiple electrofishing passes between the period 2000 and 2002, whereas two seasonal samples (spring and late summer) were collected with single pass electrofishing from 2002 (Erős \& Schmera 2010). Data from earlier samplings (i.e. from 2000 to 2002) showed that all species were captured at the reach level in this relatively small stream, even at the first pass, and relative abundance data also remained identical compared with multiple pass data (Erős 2005, Erős unpublished data). Fish were held in big buckets $(100 \times 50 \times 60 \mathrm{~cm})$ of water during fishing then identified to species level and released back to 
the stream with the exception of specimens harvested for dietary analysis. So that the intensity of seasonal samplings were consistent between years we chose only the first pass data of spring and late autumn samples from the 2000-2002 period. Altogether the results of 24 seasonal samples are evaluated in this article ( 12 years $\times 2$ seasonal samples).

We collected 421 fish on six occasions (May 2000, April 2009, August 2009, August 2010, May 2011, August 2011) to characterize functional structure of the assemblage based on diet composition (i.e. trophic function). Retained fish were euthanized with anoverdose of MS 222 and preserved in $5 \%$ formaldehyde solution for laboratory analysis. We collected only the minimum number of fish representing all size groups (>20 mm), which we thought would give reliable estimates of species specific diet. Sample number, however varied between species, depending on their rarity in the stream. We did not examine the diet of some extremely rare species (see Results), which altogether comprised less than $0.3 \%$ of the assemblage (relative abundance data). Further, some rare species were collected only in one season. Since the carpathian barbel is a strictly protected species, only dead specimens were collected and only in summer. In this season higher temperature conditions significantly increased the mortality of some sensitive species during electrofishing (Erös et al. pers. obs.).

In the laboratory we measured the standard length $(\mathrm{mm})$ and weight $(0.01 \mathrm{~g})$ of each fish. Length frequency histograms were used to distinguish two main size groups (small and large) for the most abundant five species, which comprised more than $85 \%$ of the assemblage (see Table 1). Distinction between size

Table 1. The species composition, frequency of occurence $(\mathrm{FrO} \%)$ and relative abundance $(\mathrm{A} \%)$ of fishes in the $\mathrm{Ke}$ mence stream based on spring and summer surveys of 12 years (2000-2011). Species are ordered according to their overall relative abundance at the site $(\mathrm{A} \%)$.

\begin{tabular}{lrr}
\hline & FrO\% & A\% \\
\hline Phoxinus phoxinus (L.) & 100 & 25.340 \\
Barbatula barbatula (L.) & 100 & 23.801 \\
Squalius cephalus (L.) & 100 & 18.792 \\
Alburnoides bipunctatus (Bloch) & 100 & 11.165 \\
Gobio sp. (L.) & 100 & 7.708 \\
Chondrostoma nasus (L.) & 92 & 6.686 \\
Barbus carpathicus (Kotlík, & 100 & 4.189 \\
Tsigenopoulos, Ráb \& Berrebi) & & \\
Rhodeus amarus (Bloch) & 50 & 0.748 \\
Lota lota (L.) & 71 & 0.678 \\
Leuciscus leuciscus (L.) & 83 & 0.629 \\
Vimba vimba (L.) & 17 & 0.086 \\
Salmo trutta m. fario (L.) & 25 & 0.072 \\
Esox lucius (L.) & 13 & 0.043 \\
Alburnus alburnus (L.) & 4 & 0.032 \\
Blicca bjoerkna (L.) & 4 & 0.011 \\
Carassius gibelio (Bloch) & 8 & 0.007 \\
Rutilus rutilus (L.) & 4 & 0.005 \\
Romanogobio vladykovi (Fang) & 4 & 0.004 \\
Barbus barbus (L.) & 4 & 0.003 \\
Cobitis elongatoides (Băcescu \& Maier) & 4 & 0.002 \\
Total number of fish & & 23329 \\
\hline & &
\end{tabular}

classes corresponded to $\leq 50$ or $>50 \mathrm{~mm}$ for the stone loach (Barbatula barbatula), the gudgeon (Gobio sp.), the European minnow (Phoxinus phoxinus), and the spirlin (Alburnoides bipunctatus), whereas to $\leq 90$ or $>90 \mathrm{~mm}$ for the chub (Squalius cephalus). With the exception of the chub, these species are small bodied and rarely exceed $10 \mathrm{~cm}$. We did not distinguish size groups for the other, relatively rare species (see Fig. 1). The stomach (stone loach and burbot Lota lota) or the anterior one third of the gut (all other species) was examined. We calculated the frequency of occurrence (\%), and the volumetric percentage (\%) of the dietary items (Hyslop 1980) for each species and size groups pooled over all years, but separately for spring and summer seasons. Preliminary analyses indicated that diet data from different years showed the same pattern within seasons for the examined species (Czeglédi 2012).

We performed the diet analyses at two main resolution levels. First, we identified food composition at the lowest taxonomic level possible (usually genus and family for stream macroinvertebrates). Here we were interested to determine in detail which macroinvertebrate taxa form the diet of the species from the available resources (Czeglédi 2012, Czeglédi \& Erös 2012). Second we evaluated the data at a resolution which refers to larger scale ecosystem function of fish, for example feeding of terrestrial matter vs aquatic material or plant material vs aquatic invertebrates. Here we distinguished five major diet groups as follows: 1) stream macroinvertebrates, 2) periphyton (mainly filamentous algae and diatoms), 3) terrestrial macroinvertebrates, 4) fish, 5) flying imagos of aquatic insects (hereafter aquatic fallen organisms). For simplicity only the results of the latter analyses are shown in this article. Finally, we multiplied the relative abundance data (\%) of each fish species with the pooled diet composition data of the corresponding species (volume $\%$ ) for each sampling occasion $(n=24)$ and scaled the values to $100 \%$ to estimate long term variability in assemblage level trophic function (see Fig. 2b).

\section{Statistical analyses}

We examined the effects of species, season (spring and summer) and size (the latter only for the five most common species see above) on diet contents (volume \%) using cluster analysis. We used the Euclidean distance and the Unweighted Pair Group Means algorithm (UPGMA) for classification (see e.g. Pusey et al. 2010). Significant groups of samples in the cluster diagrams were identified according to the randomization method of Jaksić \& Medel (1990). This method employs a bootstrap randomization of the raw data (fish species samples $\times$ variation partitions extracted from diet data) to generate a distribution of Euclidean distances reflecting the null hypothesis of no ordinate source of variation in the diet among the investigated fish-season-size group samples (Gotelli \& Graves 1996). Data were iterated 10,000 times and their distributions were used to find the critical value of distance below which the probability of occurrence by chance is < 5 \% (Jaksić \& Medel 1990; Specziár \& Rezsu 2009).

We used standardized principal component analysis (i.e. correlation matrix based PCA, Legendre \& Legendre 1998) to examine temporal trajectories in the relative abundance of species $(\%)$ in a multivariate space. For this purpose species with a relative abundance of less than $1 \%$ were pooled together. These rare species (13 altogether) comprised less than $3 \%$ of the overall relative abundance of the assemblage (see Table 1). Consequently, the data matrix for this analysis was based on 24 

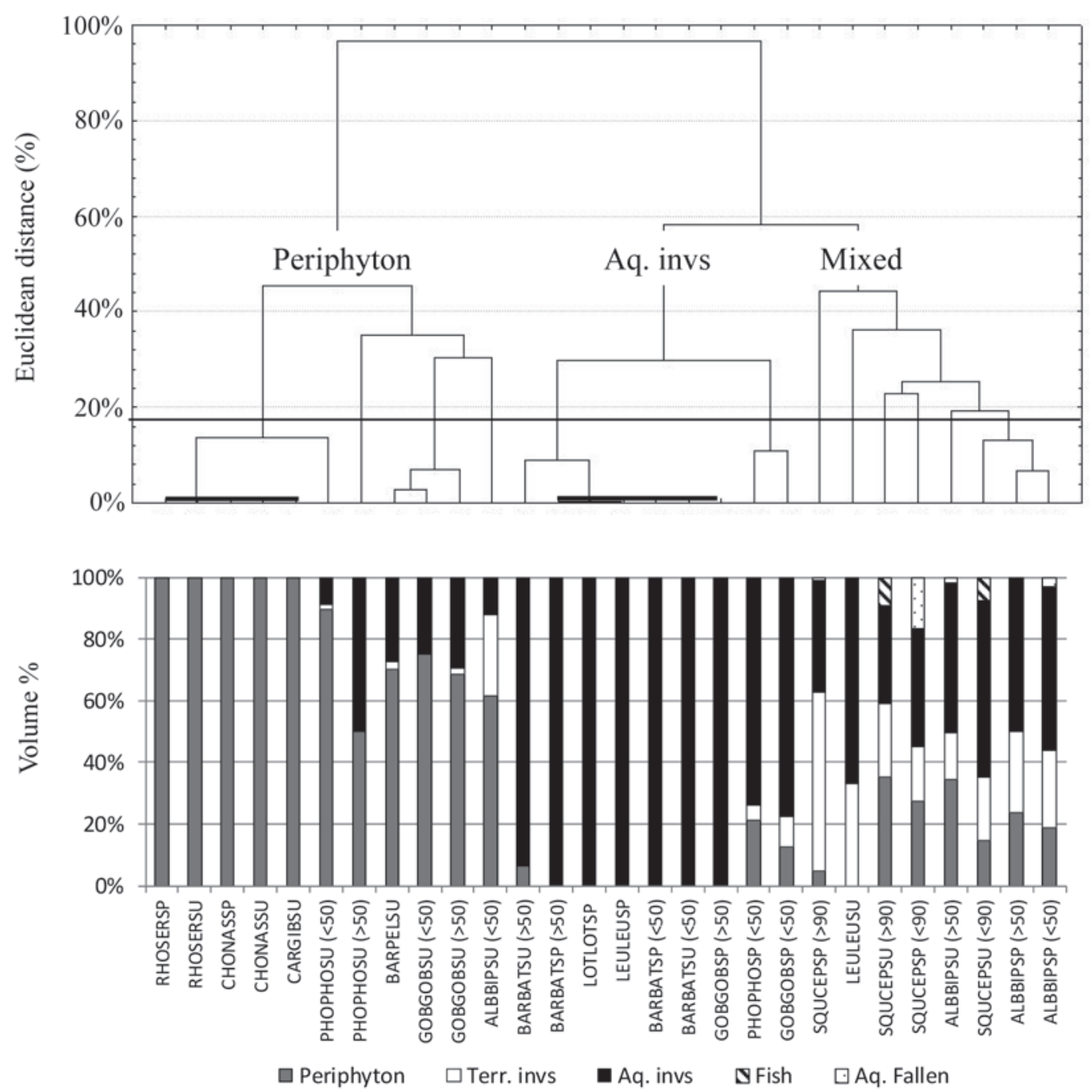

Fig. 1. Dendrogram of diet composition data of the main assemblage constituting species in the Kemence stream using the Unweighted Pair Group Means algorithm. The bootstrap analysis indicated significantly distinct clusters at the value of 17.4 . which is indicated by a continuous line in the figure. Species abbreviations are as follows. RHOSER - bitterling; CHONAS - nase; CARGIB - gibel; PHOPHO - minnow; BARPEL - Carpathian barbel; GOBGOB - gudgeon; ALBBIP - spirlin; BARBAT - stoneloach; LOTLOT - burbot; LEULEU - dace; SQUCEP - chub. Abbreviations also denote season and fish size (example) as follows. SP spring; SU - summer; <50. less than $50 \mathrm{~mm}$; $>50$ more than $50 \mathrm{~mm}$.

objects ( 12 years $\times 2$ seasonal samples) and 8 variables (relative abundance of 7 common species and the rare species group). Similarly, we used standardized PCA to examine temporal trajectories in the estimated changes in fish trophic function. Here, the data matrix was based on 24 objects, and the estimated volumetric data $(\%)$ of the 5 major diet groups (see above) comprised the variables. The percentage data (\%) were square root transformed prior to both analyses (Legendre \& Legendre 1998). Note, that this is actually the Hellinger transformation of the pure abundance data (Legendre \& Gallagher 2001).

We used "time lag regression analysis" to test for predefined temporal patterns in the assemblage using both the taxonomic and functional data (for details, see Collins et al. 2000). In this analysis a significant positive linear relationship between the time lag (i.e. number of sampling occasions) and a multivariate distance measure of community samples indi- cates directional change in time. If the distance between samples does not change as time lags increase, then the examined community structure is considered to be stable. Finally, a significant negative linear relationship is indicative of an unstable community with convergence (i.e. similarity) to an earlier sampling period. However, instead of using linear regression as used by Collins et al. (2000), we used Spearman rank correlation analysis to quantify the relationship between time lag and community distance, because we operated with occasions and not with exact dates in the analysis. Hereafter, we refer to the analysis as time lag analysis. We used the Euclidean distance of the square root transformed percentage data (i.e. Hellinger distance matrix) for both analyses using the same data matrices as for the two PCAs (i.e. relative abundance data and percentage volumetric diet data for the taxonomic and functional structure, respectively). 

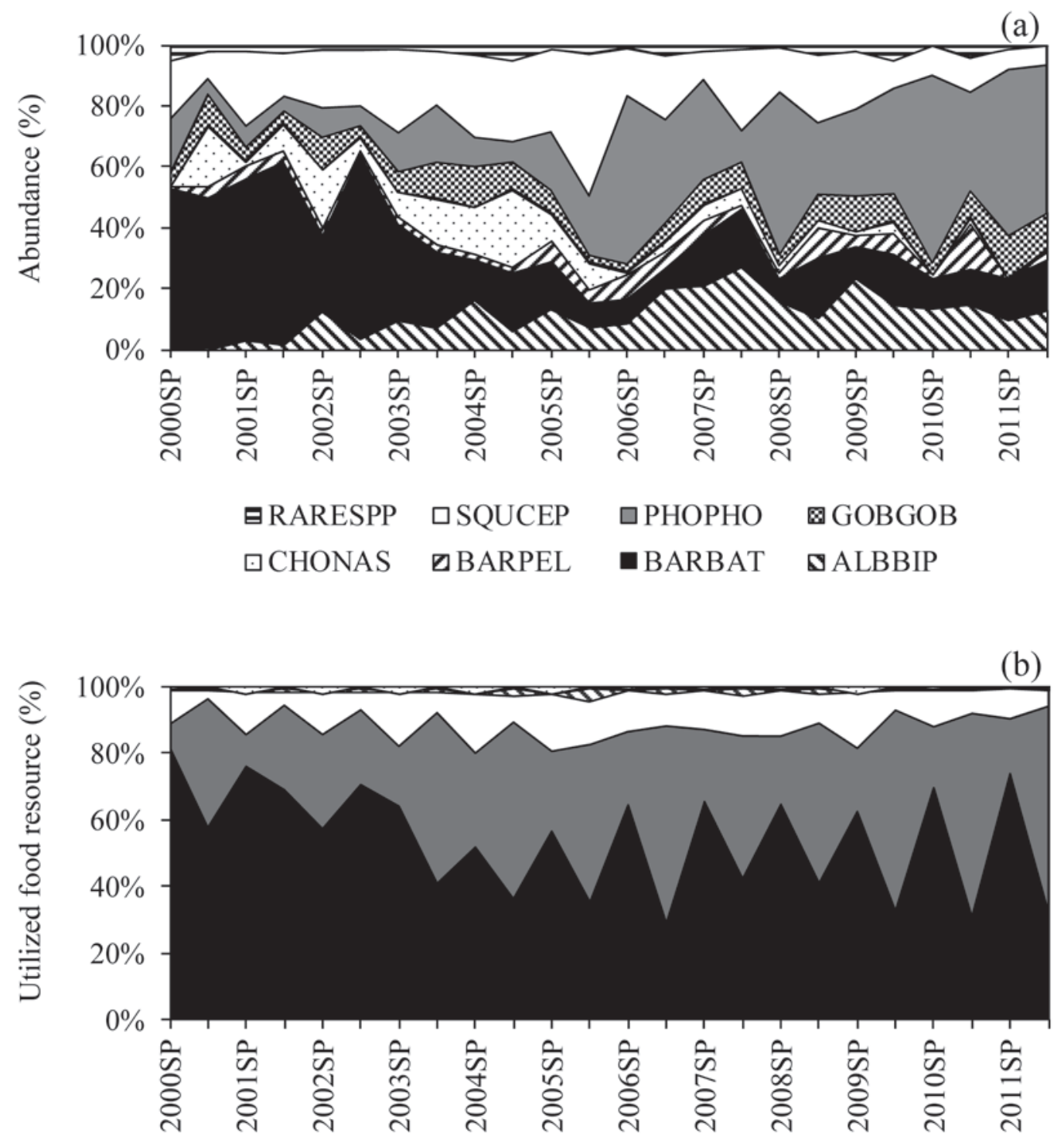

Aq. invs $\square$ Periphyton $\square$ Terr. invs $\boldsymbol{\nabla}$ Fish $\boxminus$ Aq. fallen

Fig. 2. Temporal changes in the relative abundance of fishes (a) and in their estimated assemblage level diet composition (b) in the Kemence stream between 2000 and 2011.

The statistical analyses were performed with the program Statistica 8.0 (StatSoft, Inc) and with the freely available software package $\mathrm{r}$ (R Development Core team, 2011) using the vegan package (Oksanen et al, 2010).

\section{Results}

\section{Assemblage composition and trophic function}

A total of 23,329 specimens representing 20 species was surveyed during the 12 years (Table 1). Of these the European minnow (hereafter minnow), the stone loach, the chub, the spirlin, the gudgeon, the nase and the Carpathian barbel were abundant with other species comprising less than $3 \%$ of the assemblage.

The cluster analysis of diet data showed the main effect of season and to a lesser extent of species, however, the effect of size group was minimal (Fig. 1). The diet of some of the most common fishes (i.e. minnow, gudgeon, spirlin) contained mainly periphyton in summer $(>50 \%)$, while it contained mainly aquatic macroinvertebrates in spring, although feeding on periphyton and on terrestrial invertebrates was also relatively important in this season. The stone loach consumed benthic macroinvertebrates almost exclusively, irrespective of season. The diet of the chub was diverse in 
both spring and summer and contained mainly aquatic invertebrates, periphyton and terrestrial invertebrates. Of the less common and rare species the nase (Chondrostoma nasus), the bitterling (Rhodeus amarus) and the gibel (Carassius gibelio) consumed only periphyton, the burbot (Lota lota) fed only on aquatic invertebrates, while the dace (Leuciscus leuciscus) consumed aquatic invertebrates in spring, but both aquatic and terrestrial invertebrates in summer.
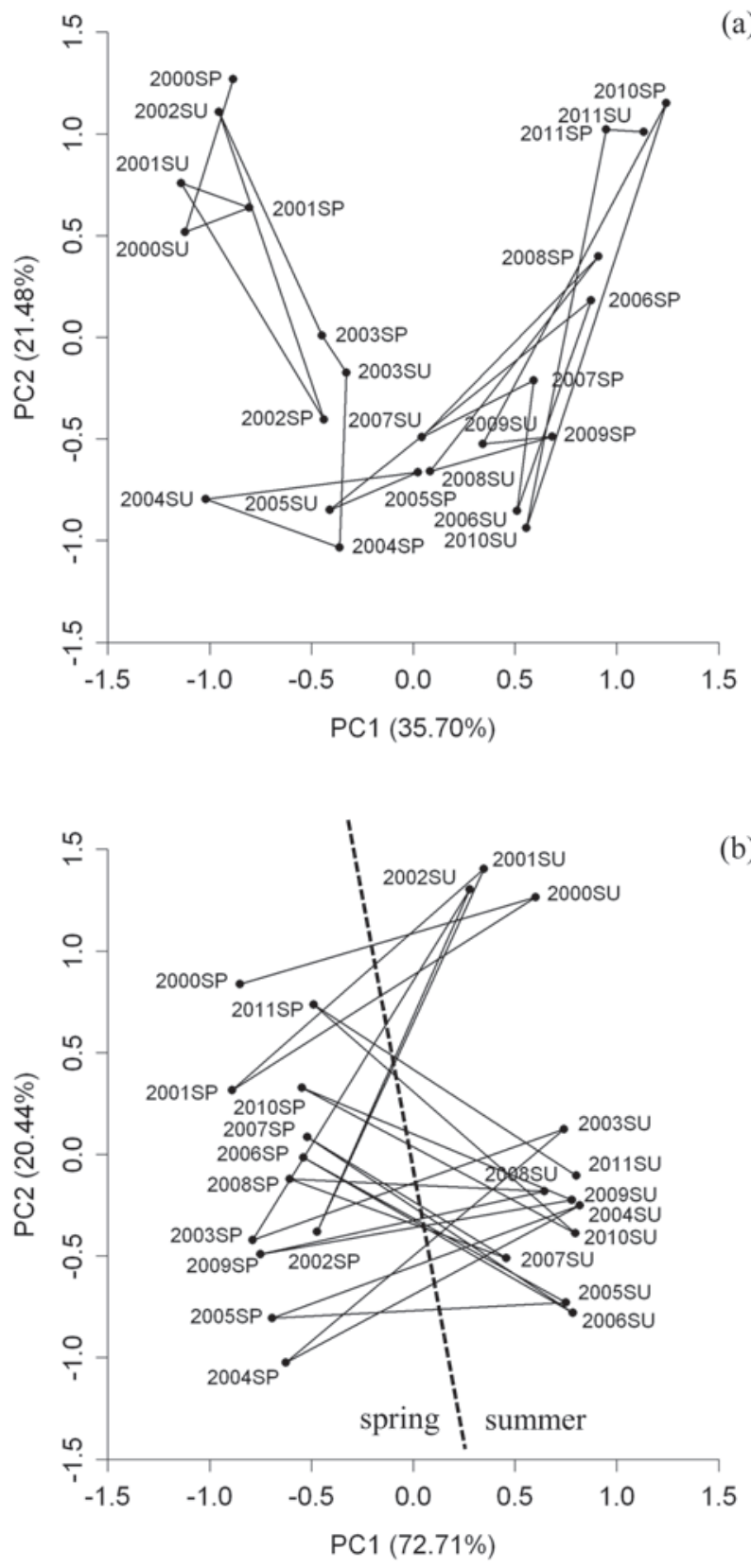

Fig. 3. PCA plots showing changes in the taxonomic (a) and functional (b) structure of the fish assemblage through time.

\section{Temporal variability in taxonomic and functional structure}

Species abundance varied from season to season, although the seven most abundant species remained dominant during the 12 years (Fig. 2a). The most notable changes included the increased abundance of the minnow, a midwater omnivore, and the decline of the stone loach, a benthic invertivore. The main trophic function of the fish assemblage remained relatively constant throughout the study period (Fig. 2b). Fish in the Kemence stream consumed aquatic macroinvertebrates and periphyton predominantly, while terrestrial invertebrates, fish and fallen aquatic invertebrates formed a relatively small portion of the diet. However, the estimations indicated relatively strong seasonality in the importance of the consumption of aquatic invertebrates vs periphyton with the importance of invertebrates increasing in spring and decreasing in summer and vica versa for periphyton.

Principal component analysis of relative abundance data indicated a directional pattern in the fish assemblages over time (Fig. 3a). The first axis (PC1 $35.7 \%$ ) was determined mainly by the changes in the two most abundant species (Table 2). The stone loach and the minnow were the most deterministic species of samples from the earliest (negative values) and the latest (positive values) sampling periods, respectively. The second axis (PC2 $21.5 \%$ ) separated sam-

Table 2. Spearman correlation tests between the relative abundance data of species (taxonomic data) and the component scores of the first two PC axes (PC1 and PC2). Species abbreviations are as follows. ALBBIP, spirlin; BARBAT, stoneloach; BARPEL, Carpathian barbel; CHONAS, nase; GOBGOB, gudgeon; PHOPHO, minnow; SQUCEP, chub; RARESPP, rare species.

\begin{tabular}{lcrr}
\hline Taxonomic data & $\mathbf{N}$ & Spearman $\mathbf{r}$ & $\boldsymbol{p}$-level \\
\hline PC1 \& ALBBIP & 24 & 0.664 & $<0.001$ \\
PC1 \& BARBAT & 24 & -0.745 & $<0.001$ \\
PC1 \& BARPEL & 24 & 0.108 & 0.616 \\
PC1 \& CHONAS & 24 & -0.645 & 0.001 \\
PC1 \& GOBGOB & 24 & 0.119 & 0.579 \\
PC1 \& SQUCEP & 24 & -0.443 & 0.030 \\
PC1 \& PHOPHO & 24 & 0.937 & $<0.001$ \\
PC1 \& RARESPP & 24 & -0.481 & 0.017 \\
PC2 \& ALBBIP & 24 & -0.487 & 0.016 \\
PC2 \& BARBAT & 24 & 0.420 & 0.041 \\
PC2 \& BARPEL & 24 & -0.555 & 0.005 \\
PC2 \& CHONAS & 24 & -0.453 & 0.026 \\
PC2 \& GOBGOB & 24 & -0.223 & 0.296 \\
PC2 \& SQUCEP & 24 & -0.488 & 0.016 \\
PC2 \& PHOPHO & 24 & 0.045 & 0.834 \\
PC2 \& RARESPP & 24 & -0.486 & 0.016 \\
\hline
\end{tabular}


ples with the relative dominance of the most abundant species (positive values) from samples with species of intermediate abundance values (negative values). On the contrary, PCA of diet data (Fig. 3b) showed a relatively clear separation of samples by season along PC1 $(72.7 \%)$. Here, invertebrates of various origin (i.e. aquatic, terrestrial and aquatic fallen) dominated spring samples (negative values), while the consumption of periphyton and to a smaller extent fish was characteristic of the summer samples (positive values) (Table 3). The second axis (PC2 20.4\%) was not clearly interpretable. This axis rather contributed to the separation of samples by season together with PC1.Time lag analysis revealed a directional change in the relative abundance data of taxonomic structure (Fig. 4a; $\mathrm{r}_{\mathrm{S}}=0.666 ; p<0.001$ ). However, diet data did
Table 3. Spearman correlation tests between the relative abundance of diet components (functional data) and the component scores of the first two PC axes (PC1 and PC2). Diet components are abbreviated as follows. Aq. Invs.: stream macroinvertebrates; Aq. Fallen.: flying imagos of aquatic insects; Terr. Invs.: terrestrial macroinvertebrates.

\begin{tabular}{lccr}
\hline Functional data & N & Spearman r & $\boldsymbol{p}$-level \\
\hline PC1 \& Aq. Invs. & 24 & -0.763 & $<0.001$ \\
PC1 \& Periphyton & 24 & 0.906 & $<0.001$ \\
PC1 \& Terr. Invs. & 24 & -0.657 & $<0.001$ \\
PC1 \& Fish & 24 & 0.795 & $<0.001$ \\
PC1 \& Aq. Fallen & 24 & -0.771 & $<0.001$ \\
PC2 \& Aq. Invs & 24 & 0.640 & 0.001 \\
PC2 \& Periphyton & 24 & -0.347 & 0.097 \\
PC2 \& Terr. Invs. & 24 & -0.627 & 0.001 \\
PC2 \& Fish & 24 & -0.105 & 0.627 \\
PC2 \& Aq. Fallen & 24 & -0.449 & 0.028 \\
\hline
\end{tabular}

Fig. 4. Hellinger distance based similarity of taxonomic (a) and functional (b) fish assemblage data plotted against time lag (spring and summer surveys from 2000 spring to 2011 summer). See methods for further details.
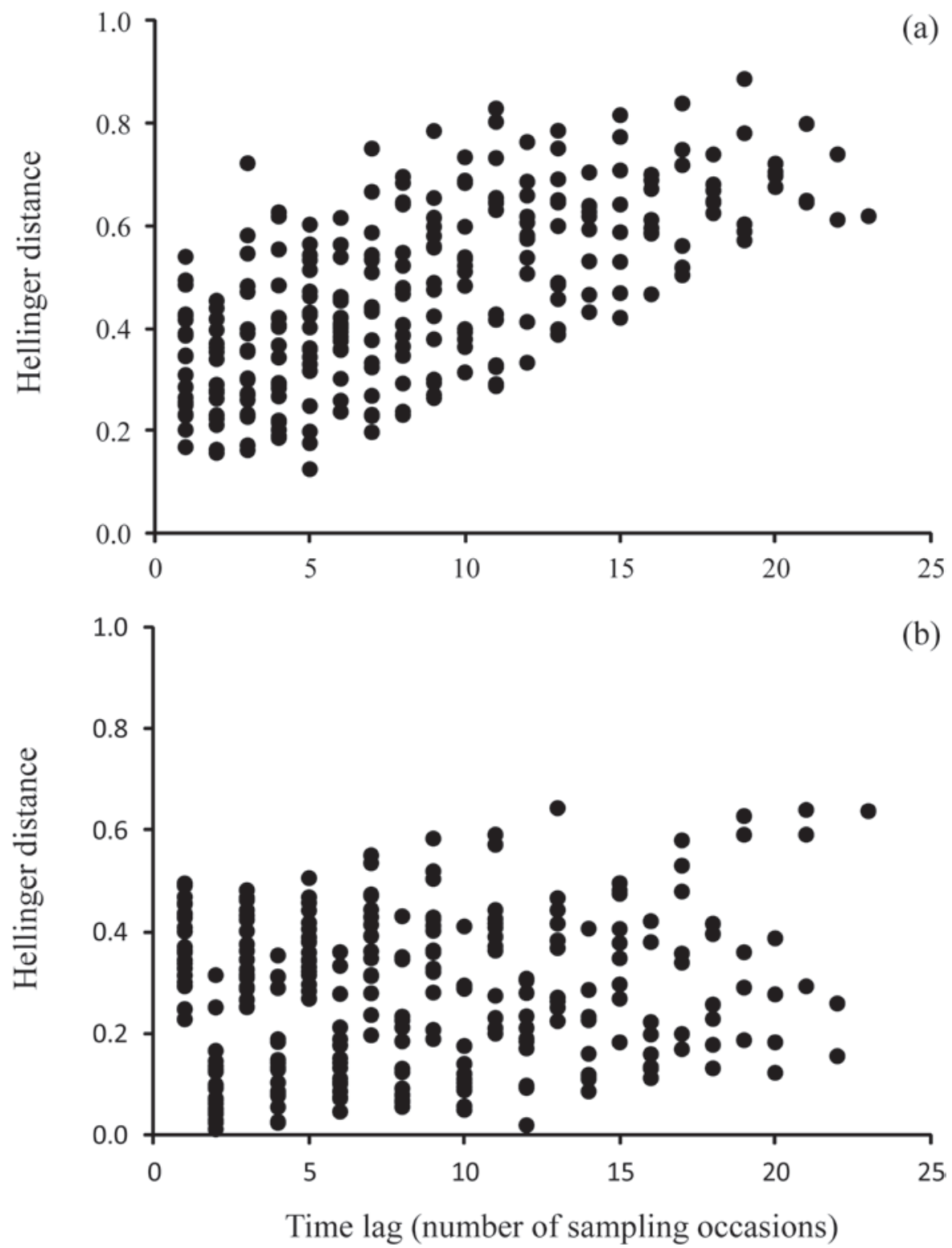
not show either directional changes or convergence, thus functional structure proved to be stable based on this analysis over the 12 years period (Fig. $4 \mathrm{~b} ; \mathrm{r}_{\mathrm{S}}$ $=0.047 ; p=0.422$ ), although it showed seasonal periodicity.

\section{Discussion}

We found the occurrence of the most abundant species was persistent, while their relative abundance was variable. Rare, satellite species formed only a very small proportion of the assemblage on each sampling occasion. They influenced patterns in species richness (detailed data are not shown here, for this see Erös \& Schmera 2010), but contributed little to variations in relative abundance. Assemblage level trophic function of fish proved to be relatively stable, although it showed clear seasonality. Temporal variability in taxonomic composition indicated that seasonal differences in fish trophic function were due to a switch to alternate food resources of the same species between seasons and not due to mass immigration of other species from outside the study area. These results thus show that local processes influenced both taxonomic and functional fish assemblage dynamics in the Kemence stream, while the relative role of regional scale (i.e. colonization) processes proved to be low and influenced only patterns in species richness.

Although both stable and temporarily highly variable assemblages have been described in the literature (Matthews 1998, Grossmann et al. 1998, Erös \& Grossman 2005b), our study concurs with several studies from other biogeographic regions (e.g. Eby et al. 2003, Magalhães et al. 2007), which justified persistence in the occurrence, and resilience, but temporal variability in the abundance of the main assemblage constituting species. It is likely that temporal fluctuations in the relative abundance of the most abundant seven species were mainly driven by hydrologic changes in the Kemence stream. This is because time lag analysis indicated strong directional changes in the fish assemblage, and former studies from this system showed the legacy of a one in a hundred year flood on the successional dynamics of species diversity (Erös et al. 2003, Erős \& Schmera 2010). Small water column species (like the minnow or the spirlin) are especially prone to the erosive effect of floods compared with benthic species (Schlosser 1982, Schlosser 1985). Thus it is not surprising that their relative abundance increased relatively consistently after this extreme flood event, which happened in 1999, just before our long-term surveys started (Erős et al. 2003, Erős \& Grossman 2005b). Unfortunately, however, we could not test the relative influence of high vs low flows on fish assemblage dynamics directly, due to the lack of detailed hydrologic data from the stream.

Contrary to the directional change observed in the taxonomic data set, assemblage level trophic function remained relatively stable throughout the study period as indicated by the time lag analysis (Collins et al. 2000), despite clear seasonality in food resource use. However, the basic diet data showed that increased consumption of periphyton in summer moderately influenced fish trophic function. For example, diet analyses showed that assemblage level proportion of periphyton in the diet can increase by more than $40 \%$ from spring to summer (Fig. 2) and these seasonal shifts in function were clearly mirrored in the PCA, and in the oscillating pattern of time lag analysis. The switch to periphyton can be explained by the decline of aquatic invertebrates from spring to summer in this system (Erös et al. 2005), which has also been shown in other studies (Angermeier 1982, Schlosser \& Angermeier 1990).

Previous studies about the temporal variability in functional organization of stream fishes used guild based categorizations for characterizing the function of individual species (e.g. Higgins 2009, Beugly \& Pyron 2010, Pyron et al. 2011). However, these categorizations (e.g. invertivore, omnivore, piscivore) are limited in predicting which diet components form the major part of the diet. They also do not really allow the sorting of a certain species to more than one trophic function, which is inevitable for a more reliable estimation of assemblage level trophic function of fish in the ecosystem. Although our approach has limitations, (because we did not have the possibility to examine diet in each sampling occasion, but used only estimations from some seasons and years), we believe that by using direct diet analysis we gave a more reliable estimation of fish trophic function at both the species and the assemblage levels. In the Kemence stream, many species were omnivores, feeding on on benthic invertebrates, periphyton and terrestrial organisms. In addition the proportion of these categories showed strong seasonal variation within and between species in the "omnivore group". Some species were, however specific in feeding and proved to be strictly benthic invertivore (stone loach) or periphyton eater (nase) irrespective of season. These patterns in seasonality and species specific functions cannot really be characterized by using feeding guilds for functional analyses. 
Our study expands former studies on the relationship between taxonomic and functional organization of fishes by using a temporal dimension. Actually, this is the first study, to our knowledge, which directly examines the relationship between the temporal variability of taxonomic and functional structure. Our findings clearly show that taxonomic variability did not significantly influence the trophic function based temporal variability of the fish assemblage in the Kemence stream. Although temporal variability in abundance yielded some changes in the importance of the two main functional roles (i.e. feeding on aquatic invertebrates vs periphyton), seasonal changes in resource use were clearly more important in shaping patterns in trophic function than changes in relative abundance through time (see Fig. 2). This work thus indicates the importance of local processes in influencing the organization of this fish assemblage, because seasonal differences and the changes in the relative abundance of the resident species influenced the variability of the assemblage more than dispersion dynamics of a variety of non resident (satellite) species from the recipient River Ipoly.

It should be emphasized that the Kemence stream is a submontane stream. As such it has a peripheral position in the stream network and filters species with relatively specific abiotic requirements, because of its low depth, stony substrate etc. Temporal variability in taxonomic and functional structure maybe larger in more lowland areas and especially in human altered landscapes (Erös et al. 2012), where assemblage dynamics of a more diverse pool of species (including high rates of colonization dynamics) may also yield diverse relationships between long-term taxonomic and functional variability. Consequently, there is a need for more intensive testing of temporal variability patterns from a variety of stream systems including other biogeographic regions to increase our understanding about the relationship between temporal variability in assemblage composition and ecosystem level function of stream fish assemblages.

\section{Acknowledgements}

We would like to express our thanks to András Specziár for his comments on the ms and in the bootstrap analysis, Péter Sály for his help with the PCA analysis and in constructing Fig. 4, and András Sevcsik and Balázs Tóth as well as numerous other people for their help in many phases of the field work. This study was partly supported by the National Biodiversity Monitoring Program of the Ministry of Environment and Water, and the OTKA PD 77684 and K104279 research funds. This research was also realized in the frames of TÁMOP 4.2.4.A/211-1-2012-001 "National Excellence Program - Elaborating and operating an inland student and researcher personal support system convergence program". The project was subsidized by the European Union and cofinanced by the European Social Fund. The work of Tibor Erős was also supported by the János Bolyai Research Scholarship of the Hungarian Academy of Sciences.

\section{References}

Angermeier, P. L., 1982: Resource seasonality and fish diets in an Illinois stream. - Environ. Biol. Fish 7: 251-264.

Berg, M. P. \& Bengtsson, J., 2007: Temporal and spatial variability in soil food web structure. - Oikos 116: 1789-1804.

Beugly, J. \& Pyron, M., 2010: Temporal and spatial variation in the long-term functional organization of fish assemblages in a large river. - Hydrobiologia 654: 215-226.

Collins, S. L., Micheli, F. \& Hartt L., 2000: A method to determine rates and patterns of variability in ecological communities. - Oikos 91: 285-293.

Czeglédi, I., 2012: Functional organization and temporal dynamics of fishes in a submontane stream. - MS thesis, Debrecen University, $50 \mathrm{pp}$.

Czeglédi, I. \& Erős, T., 2012: Diet of five fish species in a Hungarian highland stream. - Hidrológiai Közlöny 92: 15-17. (in Hungarian with a summary in English)

Eby, L. A., Fagan, W. F. \& Minckley, W. L., 2003: Variability and dynamics of a desert stream community. - Ecol. Appl. 13: $1566-1579$.

Erös, T., 2003: Temporal variations in the structure and function of fish assemblages along a submontane stream continuum. - Hidrológiai Közlöny 83: 42-44. (in Hungarian with a summary in English)

Erös, T., 2005: Organization of fish assemblages in streams the influence of habitat structure. - PhD thesis, Loránd Eötvös University, Budapest, pp. 1-124

Erös, T., 2007: Partitioning the diversity of riverine fish: the roles of habitat types and non-native species. - Freshw. Biol. 52: 1400-1415.

Erős, T., Botta-Dukát, Z. \& Grossman, G. D., 2003: Assemblage structure and habitat use of fishes in a Central-European submontane stream: a patch based approach. - Ecol. Freshw. Fish 12: 141-150.

Erős, T. \& Grossman, G. D., 2005: Fish biodiversity in two Hungarian streams - a landscape based approach. - Arch. Hydrobiol. 162: 53-71.

Erős, T. \& Grossman, G. D., 2005: Effects of within patch habitat structure and variation on fish assemblage characteristics in the Bernecei stream, Hungary. - Ecol. Freshw. Fish 14: 256-266.

Erős, T., Sály, P., Takács, P., Specziár, A. \& Bíró, P., 2012: Temporal variability in the spatial and environmental determinants of functional metacommunity organization - stream fish in a human-modified landscape. - Freshw. Biol. 57: 1914-1928.

Erős, T., Schmera, D., Cser, B., Csabai, Z. \& Murányi, D., 2005: Composition of macroinvertebrate assemblages in two submontane streams. The influence of stream order and riffle-pool structure. - Acta. Biol. Debr. Oecol. Hung. 13: 85-94. (in Hungarian with a summary in English).

Erős, T. \& Schmera, D., 2010: Spatio-temporal scaling of biodiversity and the species-time relationship in a stream fish assemblage. - Freshw. Biol. 55: 2391-2400. 
Gilliam, J. F., Fraser, D. F. \& Alkins-Koo, M., 1993: Structure of a tropical stream fish community: a role for biotic interactions. - Ecology 74: 1856-1870.

Gotelli, N. J., \& Graves, G. R., 1996: Null Models in Ecology.Smithsonian Institution Press, Washington DC and London.

Grossman, G. D., Moyle, P. B. \& Whitaker, J. O. Jr., 1982: Stochasticity in structural and functional characteristics of an Indiana fish assemblage: a test of community theory. - Am. Nat. 120: 423-454.

Grossman, G. D., Dowd, J. F. \& Crawford, M., 1990: Assemblage stability in stream fishes: a review. - Environ. Manage. 14: 661-671.

Grossman, G. D., Ratajzak, R. E., Crawford, M. \& Freeman, M. C., 1998: Assemblage organisation in stream fishes: effects of environmental variation and interspecific interactions. Ecol. Monogr. 68: 395-420.

Grossman, G. D. \& Sabo, J. L., 2010: Incorporating environmental variation into models of community stability: examples from stream fish. - In: Gido, K. B. \& Jackson, D. A. (eds): Community Ecology of Stream Fishes: Concepts, Approaches, and Techniques. - American Fisheries Society, Symposium 73, Bethesda, MD, pp. 407-426.

Higgins, C. L., 2009: Spatiotemporal variation in functional and taxonomic organization of stream-fish assemblages in central Texas. - Aquat. Ecol. 43: 1133-1141.

Hyslop, E. J., 1980: Stomach contents analysis - a review of methods and their application. - J. Fish. Biol. 17: 411-419.

Jaksić, F. M. \& Medel, R. G., 1990: Objective recognition of guilds: testing for statistically significant species clusters. Oecologia 82: 87-92.

Legendre, P. \& Gallagher, D., 2001: Ecologically meaningful transformations for ordination of species data. - Oecologia 129: $271-280$.

Legendre, P. \& Legendre, L., 1998: Numerical ecology. - Elsevier, Amsterdam, The Netherlands, pp. $\mathrm{xv}+853$.

Magalhães, M. F., Beja, P., Schlosser, I. J. \& Collares-Pereira, M. J., 2007: Effects of multi-year droughts on fish assemblages of seasonally drying Mediterranean streams. - Freshw. Biol. 52: 1494-1510.

Matthews, W. J., 1998: Patterns in freshwater fish ecology. Chapman \& Hall, New York.

McGill, B. J., Enquist, B. J., Weiher, E. \& Westoby, M., 2006: Rebuilding community ecology from functional traits. Trends Ecol. Evol. 21: 178-185.

Oksanen, J., Blanchet, F. G., Kindt, R., Legendre, P., O'Hara, R. B., Simpson, G. L., Solymos, P., Stevens, M. H. H. \& Wagner, H., 2010: Community Ecology Package. - R package version 1.17-4. http://CRAN. R-project.org/package=vegan

Peres-Neto, P. R. \& Jackson, D. A., 2001: How well do multivariate data sets match? Evaluating the association of mul- tivariate biological data sets: comparing the robustness of Mantel test and a Procrustacean superimposition approach. - Oecologia 129: 169-178.

Petchey, O. L. \& Gaston, K. J., 2006: Functional diversity: back to basics and looking forward. - Ecol. Lett. 9: 741-758.

Poff, N. L., Allan, J. D., Bain, M. B., Karr, J. R., Prestegaard, K. L., Richter, B. D., Sparks, R. E. \& Stromberg, J., 1997: The natural flow regime: a paradigm for river conservation and restoration. - BioScience 47: 769-784.

Pusey, B. J., Arthington, A. H., Stewart-Koster, B., Kennard, M. \& Read, M. G., 2010: Widespread omnivory and low temporal and spatial variation in the diet of fishes in a hydrologically variable northern Australian river. - J. Fish Biol. 77: 731-753.

Pyron, M., Williams, L., Beugly, J. \& Jacquemin, S. J., 2011: The role of trait-based approaches in understanding stream fish assemblages. - Freshw. Biol. 56: 1579-1592.

R Development Core Team, 2010: R: A language and environment for statistical computing. - R Foundation for Statistical Computing, Vienna, Austria. ISBN 3-900051-07-0, URL http://www.R-project.org.

Roberts, J. H. \& Hitt, N. P., 2010: Longitudinal structure in temperate stream fish communities: evaluating conceptual models with temporal data. - In: Gido, K. B. \& Jackson, D. A. (eds): Community Ecology of Stream Fishes: Concepts, Approaches, and Techniques. - American Fisheries Society, Symposium 73, Bethesda, MD. pp. 281-299.

Schlosser, I. J., 1982: Fish community structure and function along two habitat gradients in a headwater stream. - Ecol. Monogr. 52: 395-414.

Schlosser, I. J., 1985: Flow regime, juvenile abundance, and the assemblage structure of stream fishes. - Ecology 66: 1484-1490.

Schlosser, I. J. \& Angermeier, P. L., 1990: The influence of environmental variability, resource abundance and predation on juvenile cyprinid and centrarchid fishes. - Pol. Arch. Hydrobiol. 37: 265-284.

Specziár, A. \& Rezsu, E. T., 2009: Feeding guilds and food resource partitioning in a lake fish assemblage: an ontogenetic approach. - J. Fish Biol. 75: 247-267.

Taylor, C. M., 2010: Covariation among plains stream fish assemblages, flow regimes, and patterns of water use. - In: Gido, K. B. \& Jackson, D. A. (eds): Community Ecology of Stream Fishes: Concepts, Approaches, and Techniques. American Fisheries Society, Symposium 73, Bethesda, MD, pp. 447-459.

Webb, C. T., Hoeting, J. A., Ames, G. M., Pyne, M. I. \& Poff, N. L., 2010: A structured and dynamic framework to advance traits-based theory and prediction in ecology. - Ecol. Lett. 13: $267-283$. 